\title{
Grands chantiers et matériaux, actes de la journée organisée par Basile Baudez
}

Livraisons d'histoire de l'architecture, $n^{\circ} 16,2008,204$ pages.

\section{André Guillerme}

\section{(2) OpenEdition}

\section{Journals}

Édition électronique

URL : http://journals.openedition.org/dht/1241

DOI : $10.4000 /$ dht. 1241

ISSN : 1775-4194

Éditeur :

Centre d'histoire des techniques et de l'environnement du Cnam (CDHTE-Cnam), Société des élèves du CDHTE-Cnam

\section{Édition imprimée}

Date de publication : 1 décembre 2009

ISBN : 978-2-9530779-4-0

ISSN : 0417-8726

Référence électronique

André Guillerme, « Grands chantiers et matériaux, actes de la journée organisée par Basile Baudez », Documents pour I'histoire des techniques [En ligne], 18 | $2^{\mathrm{e}}$ semestre 2009, mis en ligne le 28 avril 2011, consulté le 24 septembre 2020. URL : http://journals.openedition.org/dht/1241 ; DOI : https://doi.org/ $10.4000 /$ dht. 1241

Ce document a été généré automatiquement le 24 septembre 2020

(c) Tous droits réservés 


\title{
Grands chantiers et matériaux, actes de la journée organisée par Basile Baudez
}

Livraisons d'histoire de l'architecture, $\mathrm{n}^{\circ}$ 16, 2008, 204 pages.

\author{
André Guillerme
}

\section{RÉFÉRENCE}

Grands chantiers et matériaux, actes de la journée organisée par Basile BAUDEZ, Livraisons d'histoire de l'architecture, $\mathrm{n}^{\circ}$ 16, 2008, 204 pages.

1 La revue des jeunes chercheurs en histoire de l'architecture propose une douzaine de contributions focalisées sur les grands chantiers urbains et la fourniture de matériaux. Parmi ceux-ci, la pierre évidemment et ses composites, mais aussi les métaux. L'introduction de Basile Baudez, "ouverture d'un grand chantier ", fait un état des lieux exhaustif et fouillé comme il se doit. Dans ce terrain en friche, il prospecte quelques solides tranchées de fondation: les approvisionnements, l'organisation des chantiers, l'outillage, les chantiers militaires. Ajoutons la récupération des matériaux, thème essentiel pour connaître leur traçabilité et leur contribution au métabolisme urbain, élément important de sociabilité et d'économie dite "souterraine»: ils contribuent à «l'argent de poche » de l'ouvrier. Variable selon le matériau - totale pour l'ardoise et la tuile, le fer et le plomb - le taux moyen de recyclage des matériaux de construction, dérisoire au XX $\mathrm{XX}^{\mathrm{e}}$ siècle, est de l'ordre de dix pour cent au XIX ${ }^{\mathrm{e}}$ siècle et très probablement de l'ordre de trente un siècle auparavant: ce dernier nombre pourrait figurer l'asymptote de la récupération en Occident, comme le laissent supposer les récentes publications de Sabine Barles, L'invention des déchets (France 1790-1970), Seyssel, Champ Vallon, 2005, et Philippe Bernardi, Il reimpiego in architettura : recupero, trasformazione e uso, Rome, Ecole française, 2009. 
2 Dominique Massounie, dans «les chantiers de la fontaine de Grenelle (1739-1745)» (pp. 59-70), pose un regard très intéressant sur ce monument dédié aux quatre saisons dont l'objectif vise «à montrer que l'abondance qui règne dans Paris ne soufre aucune interruption durant le cours de l'année » (p. 63), une fontaine dont les quatre génies « assaisonnent » la capitale arrosée par la Seine et la Marne faisant fleurir le commerce. Guillaume Fonkenell se penche sur «l'approvisionnement du chantier de l'arc de triomphe du Carrousel ; construction et restauration (1806-1943)» (pp. 71-86) : pierre, marbre, métal, les matériaux sont interrogés dans leur stockage, leur mise en œuvre, leur usure avec le temps. Notons que le ciment «métallique» (p.77) proposé pour remplacer les pierres détériorées ne date pas de 1850 ; il sert déjà à luter les cornues et étanchéifier les pilons dans les laboratoires de chimie, mélange de litharge ou de calamine avec de l'argile. Comme le suggèrent plusieurs articles - Massounie, Beisson, Fonkenell -, le plomb apparaît comme un grand matériau urbain préindustriel absent des recherches passées. Le plomb me paraît être le métal le plus commun de la construction : il couvre, bouche, peint et transporte. Son avenir historique est encore à édifier. Métal très convoité, volé, fondu, dissout pour donner la céruse et le minium, recuit - la toiture de Notre-Dame de Paris sert à faire les fosses à tan de Seguin à Boulogne pendant la Révolution - le plomb est aussi très présent dans le sol qui filtre les eaux de pluie acide. Il maintient les vitres, scelle les pierres, remplace l'argent... Il est le composant essentiel de la peinture à l'huile, blanc de Venise, d'Espagne, de Hollande, de Clichy : très toxique.

3 L'article sur les « grands chantiers et matériaux à l'ère du béton » de Georges Beisson (pp.125-138) est copieux, illustré et dense en idées plus qu'en faits. On part de l'hypothèse que le béton est un matériau vulgaire qui gagne sa noblesse dans l'Entredeux-guerres. Il insiste sur la plasticité que donne Auguste Perret au Musée des travaux publics de Paris, siège aujourd'hui du Conseil économique et social : un chantier dont l'organisation exemplaire permet la mise en œuvre du béton. Néanmoins, je ne partage pas l'idée qu'il «n'y a pas de rupture à la fin du XIX siècle dans l'organisation des chantiers " (p. 132) : il faut distinguer les travaux publics (Nathalie Montel a bien montré la rationalisation du modèle dans Le chantier du canal de Suez, Paris, Presses de l'ENPC, 1996) et le bâtiment. Et encore: les chantiers des grandes expositions industrielles, coloniales, universelles, toujours précipités, sont des lieux de rupture des pratiques. Les toupies de béton prêt à l'emploi (p. 133) n'apparaissent qu'au cours des années 1930 aux Etats-Unis et en Allemagne.

4 La position de Jean-Christophe Fichou sur le chantier «exceptionnel » du phare d'Armen (1867-1881) (pp.109-124) est une histoire éclairante à la gloire de Léonce Reynaud, ingénieur et directeur des Phares et Balises. En une douzaine d'années, quatre thèses ont été soutenues sur l'histoire des phares français, dont celle de Fichou, montrant combien cet équipement côtier a été porteur d'innovation : faut-il rappeler que pour vaincre définitivement la puissance de la mer, Smeaton découvre la chaux hydraulique pour construire le phare d'Eddystone au milieu du XVIII ${ }^{\mathrm{e}}$ siècle ? Mais le comportement du béton à la mer, déjà soulevé dans les années 1840 , n'est toujours pas résolu : la houle (mécanique) s'ajoute au sel (chimique) pour défaire ce qui est fait pour durer.

5 Une belle livraison qui s'occupe peu cependant des travaux publics - mais un quai, une route, un canal, sont-ils de l'architecture ? Le second œuvre - vitrerie, menuiserie, miroiterie, couverture - manque aussi. Un complément à l'ouvrage tiré du Premier 
congrès francophone d'histoire de la construction tenu à Paris en 2008 est à paraître en 2010.

AUTEUR

ANDRÉ GUILLERME

(CDHTE-Cnam) 